\title{
ERRATUM
}

\section{Erratum to : Gas Foaming Fabrication of Porous Biphasic Calcium Phosphate for Bone Regeneration}

\author{
Hyun Jung Kim • Il Kyu Park • Jae Ho Kim • Chong \\ Su Cho • Moon Suk Kim
}

Published online : 1 April 2012

(C) Springer-Verlag 2012

Erratum to : Tissue Engineering and Eegenerative Medicine,

Vol. 9, N0. 2, pp 63-68 (2012)

DOI 10.1007/s13770-012-0022-8

A Corresponding author of the paper, Dr. Moon Suk Kim would like to require to you about for author of the paper to withdraw participation. The corresponding author wishes to convey sincere regret to the editor and readers of the journal of Tissue Eng. Regen. Medicine

The online version of the original article can be found under DOI $10.1007 / \mathrm{s} 13770-012-0022-8$

Hyun Jung Kim · Il Kyu Park

Research and Development Center, Genewel Co., Ltd., Hwaseong, 445-924 Korea

Hyun Jung Kim $\cdot$ Jae Ho Kim

Department of Molecular Science and Technology, Ajou University, Suwon, 443-749 Korea

\section{Chong Su Cho}

Research Institute for Agriculture and Life Sciences, Seoul National University, Seoul, 151-921 Korea 